OPEN ACCESS

Edited by:

Daniele Santi,

Università Degli Studi di Modena e

Reggio Emilia, Italy

Reviewed by:

B. Gadella,

Utrecht University, Netherlands

Geoffry Nunzio De Iuliis,

University of Newcastle, Australia

*Correspondence:

Monica Muratori monica.muratori@unifi.it

Elisabetta Baldi

elisabetta.baldi@unifi.it

Specialty section:

This article was submitted to

Reproduction

a section of the journal

Frontiers in Endocrinology

Received: 14 September 2018 Accepted: 19 November 2018 Published: 11 December 2018

Citation:

Muratori M and Baldi E (2018) Effects of FSH on Sperm DNA Fragmentation:

Review of Clinical Studies and Possible Mechanisms of Action.

Front. Endocrinol. 9:734. doi: 10.3389/fendo.2018.00734

\section{Effects of FSH on Sperm DNA Fragmentation: Review of Clinical Studies and Possible Mechanisms of Action}

\author{
Monica Muratori ${ }^{1 *}$ and Elisabetta Baldi ${ }^{2 *}$ \\ 1 Department of Experimental and Clinical Biomedical Sciences "Mario Serio", University of Florence, Florence, Italy, \\ ${ }^{2}$ Department Experimental and Clinical Medicine, University of Florence, Florence, Italy
}

Sperm DNA fragmentation (sDF) is an important reproductive problem, associated to an increased time-to-pregnancy and a reduced success rate in natural and in vitro fertilization. sDF may virtually originate at any time of sperm's life: in the testis, in the epididymis, during transit in the ejaculatory ducts and even following ejaculation. Studies demonstrate that an apoptotic pathway, mainly occurring in the testis, and oxidative stress, likely acting in the male genital tract, are responsible for provoking the DNA strand breaks present in ejaculated spermatozoa. Although several pharmacological anti-oxidants tools have been used to reduce sDF, the efficacy of this type of therapies is questioned. Clearly, anti-apoptotic agents cannot be used because of the ubiquitous role of the apoptotic process in the body. A notable exception is represented by Follicle-stimulating hormone (FSH), which regulates testis development and function and has been demonstrated to exert anti-apoptotic actions on germ cells. Here, we review the existing clinical studies evaluating the effect of FSH administration on SDF and discuss the possible mechanisms through which the hormone may reduce sDF levels in infertile subjects. Although there is evidence for a beneficial effect of the hormone on sDF, further studies with clear and univocal patient inclusion criteria, including SDF cut-off levels and considering the use of a pharmacogenetic approach for patients selection are warranted to draw firm conclusions.

Keywords: testis apoptosis, DNA fragmentation, human spermatozoa, oxidative stress, follicle-stimulating hormone

\section{INTRODUCTION}

FSH (follicle-stimulating hormone or follitropin) is the main hormone regulating the development and the functions of male and female gonads. It is a glycoprotein heterodimer consisting of two chains, $\alpha$ (92 amino-acids) and $\beta$ (111 amino-acids) which are coupled by a non-covalent bond. The hormone acts by binding its receptor (FSHR) which belongs to the superfamily of the seven transmembrane domain G-protein-coupled receptors and is expressed in the gonads. After binding to FSHR, FSH activates the cAMP-protein kinase A cascade, which regulates gene expression through phosphorylation of CREB transcription factors [for a comprehensive review on FSR receptor signaling see (1)]. The action of FSH is influenced by the presence of both polymorphisms of FSHR, affecting the sensitivity of the receptors to the hormone (2), 
and the $\beta$ chain of the hormone, which is associated with significantly lower serum FSH levels (3). FSHR and FSH $\beta$ polymorphisms influence the response to treatment with FSH in both women $(4,5)$ and men (6). In particular, in the adult testis, FSH regulates spermatogenesis by acting on Sertoli cells and there is evidence that FSHR polymorphisms are associated with male infertility (7).

FSH is essential for induction of qualitative and quantitative maintenance of spermatogenesis (8), as also demonstrated by studies on FSHR KO animals, which present severe disturbances of testicular function, including small testis and aberrant gametogenesis (9-11). Besides hypogonadotropic hypogonadic men (12), highly purified or recombinant FSH has been proposed for the treatment of infertile normogonadotropic men with idiopathic oligozoospermia or oligoasthenoteratozoospermia (OAT). In human, several trials using FSH to treat men with alterations of spermatogenesis, in particular OAT men, have been published. Although many of these studies report improvement of sperm parameters, such as concentration and motility, the efficacy of FSH treatment for OAT subjects remains controversial $(6,13)$. Even more controversy exists regarding the effect of FSH treatment on sperm morphology (14-17). Controversy may depend on heterogeneity of the study characteristics, in particular patient inclusion criteria (including FSH basal levels, FSH $\beta$ and FSHR genotypes), the dose and the molecule of administered $\mathrm{FSH}$, the length of the treatment and the presence of nonresponding men (18). Despite such controversy, a Cochrane meta-analysis (19) including only randomized control trials in which gonadotrophins were compared with placebo or no treatment, suggests a beneficial effect of FSH treatment on live birth and pregnancy after natural conception in men with idiopathic male factor subfertility, but no significant effects after assisted reproduction techniques (ARTs). A more recent meta-analysis (20) evaluating 15 controlled clinical studies [with broader inclusion criteria respect to (19)] with overall 614 men treated with FSH vs. 661 treated with placebo or untreated, confirms the improvement of spontaneous pregnancy and reveals a significant effect also after ARTs, which is independent on the ART methodology. Interestingly, 11 studies evaluated also sperm parameters after FSH treatment and the meta-analysis of these studies indicated that the treatment induced a significant increase of sperm concentration (although with a high degree of heterogeneity of the studies) and a trend to a better progressive sperm motility. However, a meta-regression analysis of the same studies showed no significant correlation between pregnancy rate and sperm parameters (concentration, progressive motility) (20) in line with previous studies demonstrating the poor predictive value of semen parameters for attainment of pregnancy $(21,22)$. Thus, the improvement of pregnancy rate following treatment of subfertile men with FSH is likely due to effects on other sperm qualities (such as sperm DNA fragmentation (sDF), see below) or on testicular functions leading to an improvement of sperm functions necessary for the process of fertilization which are not evaluated by routine semen analysis (such as hyperactivation motility, ability to undergo acrosome reaction or increased chromatin compaction). In this respect, a recent study (23), demonstrated that treatment with FSH improves the percentage of spermatozoa able to bind hyaluronic acid in FSH responding men (i.e., men increasing total sperm count and total motile sperm count after FSH treatment). As ability to bind hyaluronic acid is indicative of higher sperm maturation (24), the study by Casamonti et al. (23) suggests that FSH may improve such testicular function. Alterations in sperm maturation process are also involved in the generation of sDF (see below).

This review focuses on the effect of FSH administration to idiopathic infertile men on sperm DNA fragmentation levels, discussing the possible mechanisms involved in the action of the hormone.

\section{Sperm DNA Fragmentation (sDF)}

The main function of spermatozoa is to deliver DNA to the oocyte at fertilization. Integrity of sperm and oocyte DNA is fundamental for development and quality of embryos. Sperm DNA integrity is often compromised in infertile men and sDF represents the most common DNA abnormality in these men (25). sDF consists in the presence of single and double DNA strand breaks in the sperm nucleus. Such breaks may occur at different levels of the sperm's life, virtually from early steps of spermatogenesis to the site of fertilization. Indeed, there is evidence that sperm DNA breaks may originate in the testis, in the epididymis, during transit in the ejaculatory ducts, following ejaculation and even during in vitro manipulation for ARTs. Many types of insults have been demonstrated to provoke DNA breaks, which act through two main pathways: an apoptotic process, leading to activation of endonucleases and a direct attack to DNA by free radicals which produces both base oxidation and strand breaks (26). The apoptotic process occurs mainly during spermatogenesis, either because of insults impairing the testicular function or because of a derailment of the chromatin condensation process during spermiogenesis $(27,28)$. Spermatozoa with apoptotic signs (including DNA breaks) are found in the ejaculate because the apoptotic process fails to complete [abortive apoptosis, (29)]. Although free radicals, at low levels, play an important role for sperm functions [such as motility and capacitation (30)], when ROS production overtakes the anti-oxidant defenses of spermatozoa several damages can be produced (31). Excessive ROS production may act virtually at any level during sperm's life (32), although evidence suggests that their action occurs mostly after spermiation (see below) and even during in vitro manipulations for ARTs $(33,34)$. The occurrence of defects in the process of chromatin compaction renders the spermatozoa particularly vulnerable to ROS attack (35). Muratori et al. (28) has recently reported that a clear overlapping between oxidative damage and DNA breaks was detected only in viable spermatozoa, whereas in the bulk of ejaculated spermatozoa (including viable and non-viable cells and where most DNA fragmented spermatozoa are non-viable) the presence of DNA breaks overlapped highly apoptotic traits. Considering that viable, DNA fragmented spermatozoa are cells where DNA damage developed more recently respect to the ejaculation (28), these results suggest that oxidative stress acts later in sperm's life, most likely during transit in the male genital tract, whereas apoptotic damage occurs earlier, 
mainly at testicular level. A recent clinical study (36) seems to confirm such hypothesis revealing that $\mathrm{sDF}$ in unviable spermatozoa is associated mainly with the presence of ultrasound signs of testicular abnormalities, whereas the DNA fragmented sperm population containing viable spermatozoa was mostly associated with clinical and ultrasound alterations of the prostate and of seminal vesicles, likely due to inflammatory statuses. There is also evidence that DNA damage may occur after ejaculation during in vitro incubations (37-39) or because of in vitro manipulation during sperm selection for ARTs $(33,34,40)$. In the latter case, DNA fragmented spermatozoa are highly motile and the damage appears to be induced by the contamination with heavy metals of density gradient preparations (33). Viable sperm with oxidative damage and/or strand breaks in their DNA are, most likely, a very dangerous sperm fraction of the ejaculate: they can actively participate in the fertilization process and give rise to embryos unable to successfully develop if the oocyte does not or only partially repairs the damage.

Many studies (41-43) reported that high levels of sDF are associated with a decrease of natural male fertility and recent meta-analyses confirmed the negative relationship between the amount of sDF and the outcomes of natural or assisted reproduction (44-46). It should be noted that important differences exist among the studies on ART outcomes, especially regarding couple inclusion criteria and methods used to evaluate sDF. Indeed, sDF may be evaluated by several methods [reviewed in (47)], among which TUNEL (Terminal deoxynucleotidyl transferase dUTP nick end labeling), COMET (also known as single-cell gel electrophoresis), SCSA (Sperm Chromatin Structure Assay) and Halosperm assays are the most popular. The problem with these methods is that they likely detect different types of DNA damages (47). In addition, these methods (with the exception of SCSA) are not standardized, thus making difficult to compare results among the studies. Recent meta-analyses grouped the studies according to the methods used to evaluate sDF and reported consistently that TUNEL and COMET methods are those that better reveal the negative association between $\mathrm{sDF}$ and pregnancy rate after ARTs $(45,46)$. TUNEL also resulted the method that better reveals the impact of sperm DNA damage on miscarriage in couples who conceived naturally or after IVF and ICSI (44).

Overall, the bulk of the studies described above suggests that sDF represents a target to treat men with idiopathic infertility. In consideration that apoptosis and oxidative stress are the main mechanisms producing DNA strand breaks (see above) possible therapies to prevent or decrease sDF are antioxidants and anti-apoptotic agents. The former have been used in several clinical studies, but, so far, reported beneficial effects are minimal. Indeed, a recent Cochrane meta-analysis (48) could not draw definitive conclusions regarding the benefit of treatment with anti-oxidant on live birth rates for infertile couples as only four low quality small randomized controlled trials were published at that time. The same meta-analysis reported also data about the effect of antioxidants on sDF levels. Even in this case, no clear conclusions could be drawn because the two trials included in the meta-analysis utilized different antioxidants in a low number of patients (48). Use of anti-apoptotic agents, on the other hand, is not feasible because of the ubiquitous role of programmed cell death in the body. A notable exception is represented by FSH which has specific anti-apoptotic (or pro-survival) effects at testicular level (49-52).

\section{Effect of Treatment With FSH on sDF Levels}

A recent meta-analysis evaluated the effect of FSH on SDF (53) including six studies with overall 383 men with idiopathic infertility treated with FSH. The meta-analysis revealed a slight but significant decrease of sDF after FSH treatment for 3 months but not of other semen parameters such as sperm concentration, motility and morphology. Of note, the studies included in the meta-analysis are extremely heterogeneous, both for inclusion criteria and FSH treatment scheme. Indeed, in three of them patients with severe oligozoospermia (54) or oligoasthenoteratozoospermia $(15,55)$ were included, in another (56), patients with at least one parameter below the WHO criteria, whereas in the paper by Garolla et al. (57) male partners of infertile couples with any kind of infertility cause (with exclusion of seminal tract infections and antisperm antibodies) were included if sperm count was above 20 millions. The only study where sDF basal levels (at the cut-off level $>15 \%$ ) were comprised in the inclusion criteria was that of Simoni et al. (6). Interestingly, Ruvolo et al. (55), demonstrated that patients with sDF levels $>15 \%$ were those showing a significant reduction in DNA sperm damage. More recently, Colacurci et al. (58) published results of a multicentric longitudinal trial including 103 infertile men treated with FSH for 3 months: the study demonstrated a slight but significant effect of the hormone on average sDF levels. Interestingly, this study evidenced that the treatment was more effective in the 48 patients showing sDF levels above $17 \%$ (median value of the caseload) and demonstrated that lifestyle habits like smoking may decrease the effectiveness of the therapy. The clinical studies included in the meta-analysis of Santi et al. (53) were heterogeneous also regarding the treatment schemes (type and dosage of FSH used) and the methods used to evaluate sDF, even if most studies employed TUNEL assay $(6,15,54,55,57)$. It should be considered that TUNEL is not a standardized method and it has been reported that even small variations in the different steps of the assay may affect greatly the measures (59). In addition, an important difference regards the detection method: TUNEL positive spermatozoa may be evaluated by flow cytometry in thousands of spermatozoa [as used in the papers by (57) and (6)] or by fluorescence microscopy in few hundreds of spermatozoa [used in $(15,54,55)]$. Discrepancies between the two detection methods are due not only to the different number of analyzed cells but also to the different sensitivity of the procedures. For these reasons, comparison of studies employing flow cytometry or fluorescence microscopy revealed that the former yields greater measures of $\mathrm{sDF}(60)$. This methodological issue can explain why the meta-analysis of Santi et al. (53) failed to find 

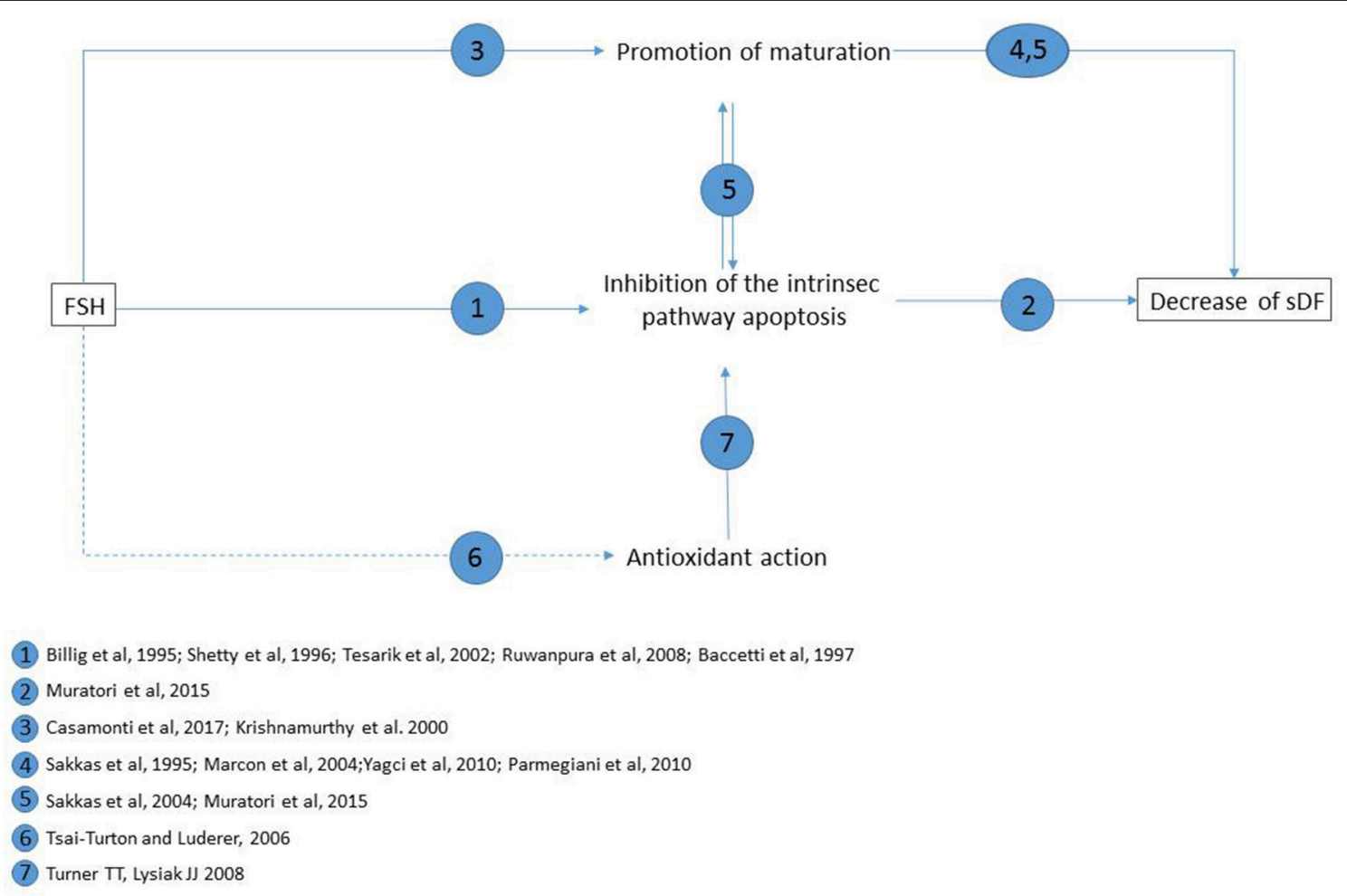

FIGURE 1 | Main possible mechanisms of FSH reducing effect on sperm DNA fragmentation levels, and supporting literature for each pathway. Straight lines: pathways demonstrated in testis or in vitro testicular cells; dotted lines: hypothesized pathway (as demonstrated to occur in pre-ovulatory follicules in vitro).

a difference in the average sDF levels after treatment when comparing FSH treated and untreated men.

There is also evidence, in the literature, that specific genotypes of FSHR (the polymorphism p.N680s) predicts responsiveness to FSH administration (6) and that the polymorphism of FSH betasubunit promoter FSHB-211 TT is associated with lower FSH levels and lower sperm counts (61). Overall these studies suggest that the use of pharmacogenetic approaches to select patients, may increase the percentage of responders to the therapy.

Clearly, larger studies are needed to confirm the ameliorative effect of FSH on sDF: such studies should be properly designed, possibly using selection criteria which include a cut-off of sDF basal levels and the above mentioned pharmacogenetic approaches. However, it must be mentioned that, due to lack of international standardized procedures to evaluate sDF, identifying a cut-off value depends strictly on the assay used to measure the parameter. At present, the only possibility is the identification of cut-off values by comparing fertile and infertile subjects in each laboratory using the chosen method to evaluate sDF among those currently available (see above).

Which is(are) the mechanism(s) through which FSH ameliorates sDF levels in the ejaculate? If we consider that most DNA fragmented spermatozoa show signs of apoptosis and chromatin immaturity (28) likely due to a derangement of the spermatogenetic process or of the chromatin maturation process, the most probable mechanisms of action of FSH consist in anti-apoptotic and maturation promoting effects at tubular level. There is evidence of anti-apoptotic effects of FSH both in the ovary and in the testis. In the ovary, the hormone is a major survival factor for follicles (62) and antagonizes the apoptosis induced by oxidative stress reducing ROS production through stimulation of the antioxidant glutathione (GSH) (63). In the testis, suppression or immunoneutralization of FSH increases apoptotic DNA fragmentation (49-51, 64). FSH suppression induces spermatogonial apoptosis predominantly via the intrinsic pathway, as an increase of caspase activity (52) and a decrease of BCL2 (51) have been demonstrated in spermatogonial cells. Consistently, in vitro studies demonstrated up-regulation of the BCL2 family member $\mathrm{Bcl} 212$ mRNA in spermatogonia of adult mice after FSH treatment (65). However, the molecular details by which $\mathrm{FSH}$ deprivation leads to activation of the apoptotic intrinsic pathway in spermatogonia is not fully clarified. In a murine model, upon deprivation of gonadotropins, the initiation of apoptosis was preceded by $\mathrm{p} 38$ MAPK activation and induction of iNOS (66) and this seems to be the case also in normal adult men $(51,52)$. FSH anti-apoptotic effects seems to occur both in Sertoli cells and in germ cells (64) and, in the latter, both before and after meiosis $(49,50,64)$. Interestingly, it has been shown that the mechanisms by which gonadotropins promote the survival of germ cells can be different depending on the cell type $(51,52)$. In Sertoli cells, FSH promotes anti-apoptotic pathways presumably trough activation of protein kinase B/AKT protein (67). These results suggest that FSH may regulate proliferation and development of male germ 
cells both indirectly, by acting on Sertoli cells, and directly by up-regulating anti-apoptotic pathways in germ cells. There is also evidence for an effect of FSH on sperm maturation. Baccetti et al. (68) reported an improvement of semen quality and ultrastructural characteristics of spermatozoa in men with high levels of apoptosis and immaturity features in their spermatozoa, supporting the anti-apoptotic and pro-maturation role of FSH in human testis. Recently, a role of FSH favoring sperm maturation has been suggested by the above mentioned study of Casamonti et al. (23), which demonstrated that FSH increases the number of spermatozoa binding to Hyaluronic acid. Although the mechanism(s) through which FSH may promote sperm maturation are mostly unknown, interestingly, a disturbance in the normal replacement of histones by protamines during spermiogenesis, leading to poor condensation of spermatid nuclei, has been demonstrated in FSHR KO mice (69). Sperm maturation is closely linked to DNA integrity. Indeed, it is during spermiogenesis that the replacement of histones with protamines occurs and, as mentioned, a derangement of this process may lead to DNA fragmentation due to lack of re-ligation of the nicks necessary for chromatin compaction $(70,71)$. In addition, there is evidence that a disturbance of the process of chromatin compaction can represent a trigger for induction of apoptosis in the testis (28). Finally, increased ability of sperm to bind to hyaluronic acid has been associated to higher chromatin compaction and decreased DNA fragmentation $(24,72)$.

As mentioned above, DNA damage can be produced also by a direct attack of ROS. Although, at present, there is no evidence of an anti-oxidant effect of FSH in the testis or in spermatogonial cells in vitro, such effect of the hormone cannot be excluded, as it reduces oxidative stress-induced apoptosis in ovarian cells (63).

\section{REFERENCES}

1. Ulloa-Aguirre A, Reiter E, Crépieux P. FSH receptor signaling: complexity of interactions and signal diversity. Endocrinology (2018) 159:3020-35. doi: 10.1210/en.2018-00452

2. Santi D, Poti F, Simoni M, Casarini L. Pharmacogenetics of G-protein-coupled receptors variants: FSH receptor and infertility treatment. Best Pract Res Clin Endocrinol Metab. (2018) 32:189-200. doi: 10.1016/j.beem.2018.01.001

3. Alviggi C, Conforti A, Santi D, Esteves SC, Andersen CY, Humaidan P, et al. Clinical relevance of genetic variants of gonadotrophins and their receptors in controlled ovarian stimulation: a systematic review and meta-analysis. Hum Reprod Update (2018) 24:599-614. doi: 10.1093/humupd/dmy019

4. Perez Mayorga M, Gromoll J, Behre HM, Gassner C, Nieschlag E, Simoni M. Ovarian response to follicle-stimulating hormone (FSH) stimulation depends on the FSH receptor genotype. J Clin Endocrinol Metab. (2000) 85:3365-9. doi: 10.1210/jcem.85.9.6789

5. Behre HM, Greb RR, Mempel A, Sonntag B, Kiesel L, Kaltwasser P, et al. Significance of a common single nucleotide polymorphism in exon 10 of the follicle-stimulating hormone (FSH) receptor gene for the ovarian response to FSH: a pharmacogenetic approach to controlled ovarian hyperstimulation. Pharmacogenet Genomics (2005) 15:451-6. doi: 10.1097/01.fpc.0000167330.92786.5e

6. Simoni M, Santi D, Negri L, Hoffmann I, Muratori M, Baldi E, et al. Treatment with human, recombinant FSH improves sperm DNA fragmentation in idiopathic infertile men depending on the FSH receptor polymorphism p.N680S: a pharmacogenetic study. Hum Reprod. (2016) 31:1960-9. doi: 10.1093/humrep/dew167
It should be mentioned that oxidative stress may produce the formation of breaks and stable DNA adducts also through a direct attack to DNA (31) and that such damage could persist following FSH treatment. The main possible mechanisms of FSH-related decrease of sDF levels are summarized in Figure 1.

\section{CONCLUSION}

Although sDF is an important reproductive problem affecting the outcomes of both natural and assisted reproduction, effective treatments to prevent or limit the sperm DNA damage in men are presently scarce. Treatment with FSH appears promising as there is evidence of a beneficial effect of the treatment on sDF (53). However, the lack of clear and univocal patient inclusion criteria contributes to the high heterogeneity of the clinical studies published so far, which does not allow to draw clear-cut conclusions about the effectiveness of the hormone on sperm DNA damage. Future studies should not only include cut-off values of $\mathrm{sDF}$ among patient inclusion criteria but also consider the pharmacogenetic evidence of FSH action to identify subjects that may not have beneficial effects from the therapy.

\section{AUTHOR CONTRIBUTIONS}

All authors listed have made a substantial, direct and intellectual contribution to the work, and approved it for publication.

\section{FUNDING}

EB is supported by Italian Ministry of University and Research (MIUR) PRIN project 2015.
7. Wu Q, Zhang J, Zhu P, Jiang W, Liu S, Ni M, et al. The susceptibility of FSHB-211G > T and FSHR G-29A, 919A > G, 2039A > $\mathrm{G}$ polymorphisms to men infertility: an association study and meta-analysis. BMC Med Genet. 18:81. doi: 10.1186/s12881-0170441-4

8. Nieschlag E, Simoni M, Gromoll J, Weinbauer GF. Role of FSH in the regulation of spermatogenesis: clinical aspects. Clin Endocrinol. (1999) 51:139-46. doi: 10.1046/j.1365-2265.1999. 00846.x

9. Kumar TR, Wang Y, Lu N, Matzuk MM. Follicle stimulating hormone is required for ovarian follicle maturation but not male fertility. Nat Genet. (1997) 15:201-4. doi: 10.1038/ng0297-201

10. Abel MH, Wootton AN, Wilkins V, Huhtaniemi I, Knight PG, Charlton HM. The effect of a null mutation in the follicle-stimulating hormone receptor gene on mouse reproduction. Endocrinology (2000) 141:1795-803. doi: $10.1210 /$ endo.141.5.7456

11. Dierich A, Sairam MR, Monaco L, Fimia GM, Gansmuller A, LeMeur M, et al. Impairing follicle-stimulating hormone (FSH) signaling in vivo: targeted disruption of the FSH receptor leads to aberrant gametogenesis and hormonal imbalance. Proc Natl Acad Sci USA. (1998) 95:13612-7.

12. Kliesch S, Behre HM, Nieschlag E. Recombinant human folliclestimulating hormone and human chorionic gonadotropin for induction of spermatogenesis in a hypogonadotropic male. Fertil Steril. (1995) 63:1326-8. doi: 10.1016/S0015-0282(16)57619-5

13. Shiraishi K, Matsuyama H. Gonadotoropin actions on spermatogenesis and hormonal therapies for spermatogenic disorders [Review]. Endocr J. (2017) 64:123-31. doi: 10.1507/endocrj.EJ17-0001 
14. Baccetti B, Piomboni P, Bruni E, Capitani S, Gambera L, Moretti E, et al. Effect of follicle-stimulating hormone on sperm quality and pregnancy rate. Asian J Androl. (2004) 6:133-7.

15. Colacurci N, Monti MG, Fornaro F, Izzo G, Izzo P, Trotta C, et al. Recombinant human FSH reduces sperm DNA fragmentation in men with idiopathic oligoasthenoteratozoospermia. J Androl. (2012) 33:588-93. doi: 10.2164/jandrol.111.013326

16. Caroppo E, Niederberger C, Vizziello GM, D'Amato G. Recombinant human follicle-stimulating hormone as a pretreatment for idiopathic oligoasthenoteratozoospermic patients undergoing intracytoplasmic sperm injection. Fertil Steril. (2003) 80:1398-403. doi: 10.1016/S0015-0282(03)02202-7

17. Efesoy O, Cayan S, Akbay E. The efficacy of recombinant human folliclestimulating hormone in the treatment of various types of male-factor infertility at a single university hospital. J Androl. (2009) 30:679-84. doi: 10.2164/jandrol.108.007278

18. Barbonetti A, Calogero AE, Balercia G, Garolla A, Krausz C, La Vignera S, et al. The use of follicle stimulating hormone (FSH) for the treatment of the infertile man: position statement from the Italian Society of Andrology and Sexual Medicine (SIAMS). J Endocrinol Invest. (2018) 41:1107-22. doi: 10.1007/s40618-018-0843-y

19. Attia AM, Abou-Setta AM, Al-Inany HG. Gonadotrophins for idiopathic male factor subfertility. Cochrane Database Syst Rev. (2013) 2013:CD005071. doi: 10.1002/14651858.CD005071.pub4

20. Santi D, Granata AR, Simoni M. FSH treatment of male idiopathic infertility improves pregnancy rate: a meta-analysis. Endocr Connect. (2015) 4:R46-58. doi: 10.1530/EC-15-0050

21. Guzick DS, Overstreet JW, Factor-Litvak P, Brazil CK, Nakajima ST, Coutifaris C, et al. Sperm morphology, motility, and concentration in fertile and infertile men. N Engl J Med. (2001) 345:1388-93. doi: 10.1056/NEJMoa003005

22. Leushuis E, van der Steeg JW, Steures P, Repping S, Bossuyt PM, Mol BW, et al. Semen analysis and prediction of natural conception. Hum Reprod. (2014) 29:1360-7. doi: 10.1093/humrep/deu082

23. Casamonti E, Vinci S, Serra E, Fino MG, Brilli S, Lotti F, et al. Short-term FSH treatment and sperm maturation: a prospective study in idiopathic infertile men. Andrology (2017) 5:414-22. doi: 10.1111/andr.12333

24. Yagci A, Murk W, Stronk J, Huszar G. Spermatozoa bound to solid state hyaluronic acid show chromatin structure with high DNA chain integrity: an acridine orange fluorescence study. J Androl. (2010) 31:566-72. doi: 10.2164/jandrol.109.008912

25. Tamburrino L, Marchiani S, Montoya M, Elia Marino F, Natali I, Cambi M, et al. Mechanisms and clinical correlates of sperm DNA damage. Asian J Androl. (2012) 14:24-31. doi: 10.1038/aja.2011.59

26. Rex AS, Aagaard J, Fedder J. DNA fragmentation in spermatozoa: a historical review. Andrology (2017) 5:622-30. doi: 10.1111/andr.12381

27. Sakkas DE, Seli GC, Manicardi M, Nijs W, Ombelet D. Bizzaro: the presence of abnormal spermatozoa in the ejaculate: did apoptosis fail? Hum Fertil. (2004) 7:99-103. doi: 10.1080/14647270410001720464

28. Muratori M, Tamburrino L, Marchiani S, Cambi M, Olivito B, Azzari C, et al. Investigation on the origin of sperm DNA fragmentation: role of apoptosis, immaturity and oxidative stress. Mol Med. (2015) 21:109-22. doi: $10.2119 /$ molmed.2014.00158

29. Sakkas D, Seli E, Bizzaro D, Tarozzi N, Manicardi GC. Abnormal spermatozoa in the ejaculate: abortive apoptosis and faulty nuclear remodelling during spermatogenesis. Reprod Biomed Online (2003) 7:428-32. doi: 10.1016/S1472-6483(10)61886-X

30. O'Flaherty C, Matsushita-Fournier D. Reactive oxygen species and protein modifications in spermatozoa. Biol Reprod. (2017) 97:577-85. doi: 10.1093/biolre/iox104

31. Aitken RJ. Reactive oxygen species as mediators of sperm capacitation and pathological damage. Mol Reprod Dev. (2017) 84:1039-52. doi: $10.1002 / \mathrm{mrd} .22871$

32. Turner TT, Lysiak JJ. Oxidative stress: a common factor in testicular dysfunction. J Androl. (2008) 29:488-98. doi: 10.2164/jandrol.108.005132

33. Aitken RJ, Finnie JM, Muscio L, Whiting S, Connaughton HS, Kuczera L, et al. Potential importance of transition metals in the induction of DNA damage by sperm preparation media. Hum Reprod. (2014) 29:2136-47. doi: 10.1093/humrep/deu204
34. Muratori M, Tarozzi N, Cambi M, Boni L, Iorio AL, Passaro C, et al. Variation of DNA fragmentation levels during density gradient sperm selection for assisted reproduction techniques: a possible new male predictive parameter of pregnancy? Medicine (2016) 95:e3624. doi: 10.1097/MD.0000000000003624

35. De Iuliis GN, Thomson LK, Mitchell LA, Finnie JM, Koppers AJ, Hedges A, et al. DNA damage in human spermatozoa is highly correlated with the efficiency of chromatin remodeling and the formation of 8-hydroxy-2'deoxyguanosine, a marker of oxidative stress. Biol Reprod. (2009) 81:517-24. doi: 10.1095/biolreprod.109.076836

36. Lotti F, Tamburrino L, Marchiani S, Maseroli E, Vitale P, Forti G, et al. DNA fragmentation in two cytometric sperm populations: relationship with clinical and ultrasound characteristics of the male genital tract. Asian J Androl. (2017) 19:272-9. doi: 10.4103/1008-682X.174854

37. Muratori M, Maggi M, Spinelli S, Filimberti E, Forti G, Baldi E. Spontaneous DNA fragmentation in swim-up selected human spermatozoa during long term incubation. J Androl. (2003) 24:253-62. doi: 10.1002/j.1939-4640.2003.tb02670.x

38. Toro E, Fernández S, Colomar A, Casanovas A, Alvarez JG, López-Teijón M, et al. Processing of semen can result in increased sperm DNA fragmentation. Fertil Steril. (2009) 92:2109-12. doi: 10.1016/j.fertnstert.2009.05.059

39. Gosálvez J, Cortés-Gutiérrez EI, Nuñez R, Fernández JL, Caballero P, LópezFernández C, et al. A dynamic assessment of sperm DNA fragmentation versus sperm viability in proven fertile human donors. Fertil Steril. (2009) 92:1915-9. doi: 10.1016/j.fertnstert.2008.08.136

40. Zini A, Nam RK, Mak V, Phang D, Jarvi K. Influence of initial semen quality on the integrity of human sperm DNA following semen processing. Fertil Steril. (2000) 74:824-7. doi: 10.1016/S0015-0282(00)01495-3

41. Evenson DP, Jost LK, Marshall D, Zinaman MJ, Clegg E, Purvis K, et al. Utility of the sperm chromatin structure assay as a diagnostic and prognostic tool in the human fertility clinic. Hum Reprod. (1999) 14:1039-49. doi: 10.1093/humrep/14.4.1039

42. Giwercman A, Lindstedt L, Larsson M, Bungum M, Spano M, Levine RJ, et al. Sperm chromatin structure assay as an independent predictor of fertility in vivo: a case-control study. Int J Androl. (2010) 33:e221-7. doi: 10.1111/j.1365-2605.2009.00995.x

43. Muratori M, Marchiani S, Tamburrino L, Cambi M, Lotti F, Natali I, et al. DNA fragmentation in brighter sperm predicts male fertility independently from age and semen parameters. Fertil Steril. (2015) 104:582-90.e4. doi: 10.1016/j.fertnstert.2015.06.005

44. Robinson L, Gallos ID, Conner SJ, Rajkhowa M, Miller D, Lewis S, et al. The effect of sperm DNA fragmentation on miscarriage rates: a systematic review and meta-analysis. Hum Reprod. (2012) 27:2908-17. doi: 10.1093/humrep/des261

45. Cissen M, Wely MV, Scholten I, Mansell S, Bruin JP, Mol BW, et al. Measuring sperm DNA fragmentation and clinical outcomes of medically assisted reproduction: a systematic review and meta-analysis. PLoS ONE (2016) 11:e0165125. doi: 10.1371/journal.pone.0165125

46. Simon L, Zini A, Dyachenko A, Ciampi A, Carrell DT. A systematic review and meta-analysis to determine the effect of sperm DNA damage on in vitro fertilization and intracytoplasmic sperm injection outcome. Asian J Androl. (2017) 19:80-90. doi: 10.4103/1008-682X.182822

47. Agarwal A, Majzoub A, Esteves SC, Ko E, Ramasamy R, Zini A. Clinical utility of sperm DNA fragmentation testing: practice recommendations based on clinical scenarios. Transl Androl Urol. (2016) 5:935-50. doi: 10.21037/tau.2016.10.03

48. Showell MG, Mackenzie-Proctor R, Brown J, Yazdani A, Stankiewicz MT, Hart RJ. Antioxidants for male subfertility. Cochrane Database Syst Rev. (2014) 2014:CD007411. doi: 10.1002/14651858.CD007411.pub3

49. Billig H, Furuta I, Rivier C, Tapanainen J, Parvinen M, Hsueh AJ. Apoptosis in testis germ cells: developmental changes in gonadotropin dependence and localization to selective tubule stages. Endocrinology (1995) 136:5-12. doi: 10.1210/endo.136.1.7828558

50. Shetty J, Marathe GK, Dighe RR. Specific immunoneutralization of FSH leads to apoptotic cell death of the pachytene spermatocytes and spermatogonial cells in the rat. Endocrinology (1996) 137:2179-82. doi: 10.1210/endo.137.5.8612566

51. Ruwanpura SM, McLachlan RI, Stanton PG, Loveland KL, Meachem SJ. Pathways involved in testicular germ cell apoptosis in immature rats 
after FSH suppression. J Endocrinol. (2008) 197:35-43. doi: 10.1677/JOE07-0637

52. Ruwanpura SM, McLachlan RI, Stanton PG, Meachem SJ. Folliclestimulating hormone affects spermatogonial survival by regulating the intrinsic apoptotic pathway in adult rats. Biol Reprod. (2008) 78:705-13. doi: 10.1095/biolreprod.107.065912

53. Santi D, Spaggiari G, Simoni M. Sperm DNA fragmentation index as a promisig predictive tool for male infertility diagnosis and treatment management - meta-analyses. RBMO (2018) 37:315-26. doi: $10.1016 /$ j.rbmo.2018.06.023

54. Garolla A, Selice R, Engl B, Bertoldo A, Menegazzo M, Finos L, et al. Spermatid count as a predictor of response to FSH therapy. Reprod Biomed Online (2014) 29:102-12. doi: 10.1016/j.rbmo.2014.02.014

55. Ruvolo G, Roccheri MC, Brucculeri AM, Longobardi S, Cittadini E, Bosco L. Lower sperm DNA fragmentation after r-FSH administration in functional hypogonadotropic hypogonadism. J Assist Reprod Genet. (2013) 30:497-503. doi: 10.1007/s10815-013-9951-y

56. Palomba S, Falbo A, Espinola S, Rocca M, Capasso S, Cappiello F, et al. Effects of highly purified follicle-stimulating hormone on sperm DNA damage in men with male idiopathic subfertility: a pilot study. J Endocrinol Invest. (2011) 34:747-52. doi: $10.3275 / 7745$

57. Garolla A, Ghezzi M, Cosci I, Sartini B, Bottacin A, Engl B, et al. FSH treatment in infertile males candidate to assisted reproduction improved sperm DNA fragmentation and pregnancy rate. Endocrine (2017) 56:416-25. doi: 10.1007/s12020-016-1037-z

58. Colacurci N, De Leo V, Ruvolo G, Piomboni P, Caprio F, Pivonello $\mathrm{R}$, et al. Recombinant FSH Improves Sperm DNA Damage in Male Infertility: A Phase II Clinical Trial. Front Endocrinol. (2018) 9:383. doi: $10.3389 /$ fendo.2018.00383

59. Muratori M, Tamburrino L, Tocci V, Costantino A, Marchiani S, Giachini C, et al. Small variations in crucial steps of TUNEL assay coupled to flow cytometry greatly affect measures of sperm DNA fragmentation. $J$ Androl. (2010) 31:336-45. doi: 10.2164/jandrol.109.008508

60. Muratori M, Forti G, Baldi E. Comparing flow cytometry and fluorescence microscopy for analyzing human sperm DNA fragmentation by TUNEL labeling. Cytometry A (2008) 73:785-7. doi: 10.1002/cyto.a. 20615

61. Ferlin A, Vinanzi C, Selice R, Garolla A, Frigo AC, Foresta C. Toward a pharmacogenetic approach to male infertility: polymorphism of folliclestimulating hormone beta-subunit promoter. Fertil Steril. (2011) 96:1344-9. doi: 10.1016/j.fertnstert.2011.09.034

62. Chun SY, Eisenhauer KM, Minami S, Billig H, Perlas E, Hsueh AJ. Hormonal regulation of apoptosis in early antral follicles: follicle-stimulating hormone as a major survival factor. Endocrinology (1996) 137:1447-56. doi: 10.1210/endo.137. 4.8625923

63. Tsai-Turton M, Luderer U. Opposing effects of glutathione depletion and follicle-stimulating hormone on reactive oxygen species and apoptosis in cultured preovulatory rat follicles. Endocrinology (2006) 147:1224-36. doi: 10.1210/en.2005-1281
64. Tesarik J, Martinez F, Rienzi L, Iacobelli M, Ubaldi F, Mendoza C, et al. In vitro effects of FSH and testosterone withdrawal on caspase activation and DNA fragmentation in different cell types of human seminiferous epithelium. Hum Reprod. (2002) 17:1811-9. doi: 10.1093/humrep/17.7.1811

65. Meehan T, Loveland KL, de Kretser D, Cory S, Print CG. Developmental regulation of the bcl-2 family during spermatogenesis: insights into the sterility of bcl-w-/- male mice. Cell Death Differ. (2001) 8:225-33. doi: 10.1038/sj.cdd.4400799

66. Vera Y, Erkkilä K, Wang C, Nunez C, Kyttänen S, Lue Y, et al. Involvement of p38 mitogen-activated protein kinase and inducible nitric oxide synthase in apoptotic signaling of murine and human male germ cells after hormone deprivation. Mol Endocrinol. (2006) 20:1597-609. doi: 10.1210/me.2005-0395

67. Gonzalez-Robayna IJ, Falender AE, Ochsner S, Firestone GL, Richards JS. Follicle-Stimulating hormone (FSH) stimulates phosphorylation and activation of protein kinase $\mathrm{B}(\mathrm{PKB} / \mathrm{Akt})$ and serum and glucocorticoidlnduced kinase (Sgk): evidence for A kinase-independent signaling by FSH in granulosa cells. Mol Endocrinol. (2000) 14:1283-300. doi: 10.1210/mend.14.8.0500

68. Baccetti B, Strehler E, Capitani S, Collodel G, De Santo M, Moretti E, et al. The effect of follicle stimulating hormone therapy on human sperm structure (Notulae seminologicae 11). Hum Reprod. (1997) 12:1955-68. doi: 10.1093/humrep/12.9.1955

69. Krishnamurthy H, Danilovich N, Morales CR, Sairam MR. Qualitative and quantitative decline in spermatogenesis of the follicle-stimulating hormone receptor knockout (FORKO) mouse. Biol Reprod. (2000) 62:114659. doi: 10.1095/biolreprod62.5.1146

70. Sakkas D, Manicardi G, Bianchi PG, Bizzaro D, Bianchi U. Relationship between the presence of endogenous nicks and sperm chromatin packaging in maturing and fertilizing mouse spermatozoa. Biol Reprod. (1995) 52:1149-55. doi: 10.1095/biolreprod52.5.1149

71. Marcon L, Boissonneault G. Transient DNA strand breaks during mouse and human spermiogenesis new insights in stage specificity and link to chromatin remodeling. Biol Reprod. (2004) 70:910-8. doi: 10.1095/biolreprod.103.022541

72. Parmegiani L, Cognigni GE, Bernardi S, Troilo E, Ciampaglia W, Filicori M. "Physiologic ICSI": hyaluronic acid (HA) favors selection of spermatozoa without DNA fragmentation and with normal nucleus, resulting in improvement of embryo quality. Fertil Steril. (2010) 93:598-604. doi: 10.1016/j.fertnstert.2009.03.033

Conflict of Interest Statement: The authors declare that the research was conducted in the absence of any commercial or financial relationships that could be construed as a potential conflict of interest.

Copyright (๑) 2018 Muratori and Baldi. This is an open-access article distributed under the terms of the Creative Commons Attribution License (CC BY). The use, distribution or reproduction in other forums is permitted, provided the original author(s) and the copyright owner(s) are credited and that the original publication in this journal is cited, in accordance with accepted academic practice. No use, distribution or reproduction is permitted which does not comply with these terms. 